\title{
CVD とガス
}

牛 川 治 憲*

\author{
Gas Usage for CVD Technology
}

Harunori USHIKAWA *

Key Words : CVD, DRAM, Logic, Film

半導体製造工程の内, CVD膜の使用工程は拡大している。本稿では, CVD膜の必要性, CVD の原 理と特徵, CVD装置の形態および代表的な膜種とガスについて解説する。

\section{1.はじめに}

半導体の高集積化は増加の一途をたどり，テク ノロジードライバーであるDRAMにおいては, 各社で64Mbitクラスの量産が行われ, 学会発表 は, Gbit クラスDRAMの発表が盛んになってい る。一方，MPUに代表される Logic においては, ゲートの薄膜化 $(2.0 \sim 3.0 \mathrm{~nm})$, 配線の低抵抗化, 配線間容量低減等を達成するため, 新規材料導入 化の検討が進みつつある。

このような状況下において，成膜技術としての CVD(Chemical Vapor Deposition) はますます 必要性が高まっており，デバイス製造において CVDは必須な技術となっている。

本稿では，なぜ次世代デバイスにCVD技術が 求められているのかを述へ，次に膜の形成原理， 代表的な成膜方法を記し，最後に，使用される膜 種とガス種について述べる。

*東京エレクトロン啝（テ107-8481 東京都港区赤坂 5-3-6 TBS放送センター)

Tokyo Electron Limited (TBS Broadcast Center, 3-6, Akasaka, 5-chome, Minato-ku, Tokyo 107-8481)

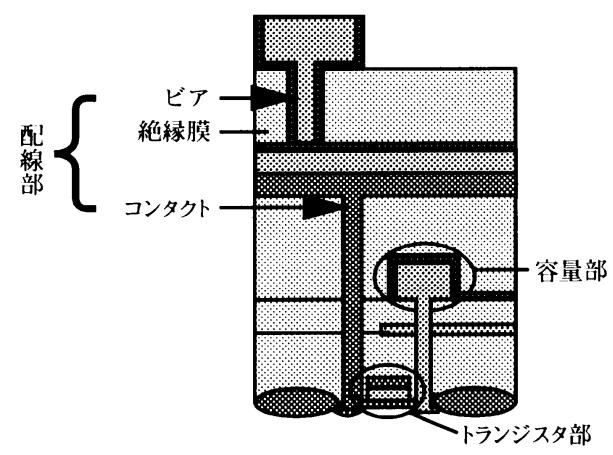

図 1 DRAM断面図

\section{2、CVD技術の必要性}

図 1，図 2 に代表的なデバイスの断面図を示す。 半導体デイバスは，大きく分けて，以下の部分か ら構成される。

(1) トランジス夕部

(2) 容量部………Logic の場合はない

(3) 配線部・コンタクト・ビア

・メタル配線

・層間絶縁膜

DRAMに代表されるメモリーでは，(2)の容量部 が重要ファクターである。一方, Logic 系におい ては, (1)，(3)のトランジスタおよび配線（特に 


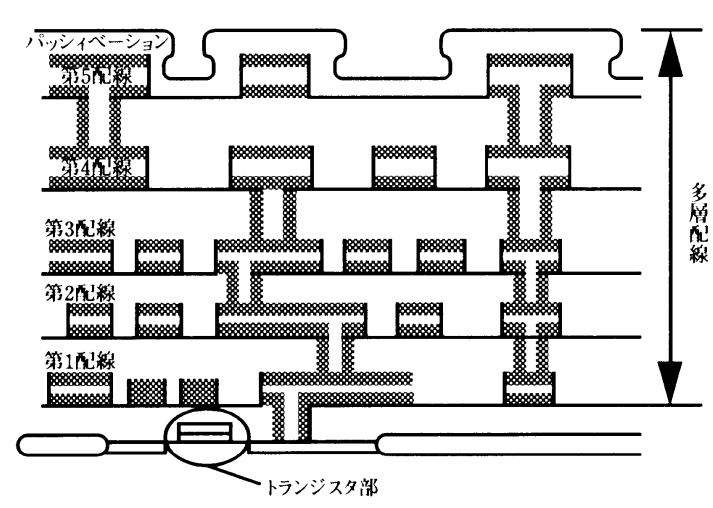

図 2 Logic 断面図

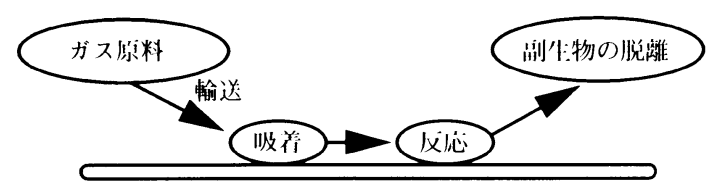

図3 CVDの基本原理

多層配線）が重要視される。

これらの断面図で例えば図 1 の容量部と $\mathrm{Si}$ ンタクトを結ぶ配線のホール径は $0.3 \mu \mathrm{m}$ 前後で あり，この断面図を見て頂ければ，半導体を製造 する上で，断差部をいろいろな膜種（膜種は後で 示す）で隙間なく埋めこむ技術が，いかに重要で あるかが分かる。

この埋めこみ技術を達成する第一候補がCVD （特に熱 CVD）技術である。

\section{CVDの基本原理}

図 3 にCVDの基本原理を簡単に記す。

大まかに分類して, 膜堆積は以下の 4 つの反応か ら成る。

(1) 原料ガスの輸送

(2) 基板上での吸着

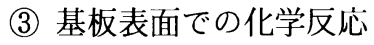

(4) 副生成物の脱離

これらの反応を，ガス種，ガス分解方法（熱，プ ラズマ), 温度 $\left(200-900^{\circ} \mathrm{C}\right)$, 圧力 $\left(10^{-1}-760\right.$ Torr $)$ などの条件を組み合わせて進行させる。特に，熱 CVDにおいては，表面反応を用いるため，埋め
こみ特性以外に以下のような特徴も持ち合わせる。

i ) 膜厚の制御性（薄いもの $4.0 \mathrm{~nm}$, 厚いもの $1.0 \mu \mathrm{m} ）$ が良好

膜厚が 3 桁異なる膜を均一性良く付けるこ とが可能

ii）膜質のコントロール性が良好

iii）生産性が高い

\section{CVD膜に要求される特性}

CVD膜の種類および用途は，極めて多様化し ており，デバイス的に要求される特性も以下のよ うに多岐に渡る ${ }^{11}$ 。

(1) 化学的安定性が高いこと（耐熱性, 耐湿性, 耐薬品性など)

(2) 加工性が良いこと

(3) 膜厚, 膜質の均一性が良いこと

(4) 密着性が良いこと

(5) 下地と上地膜が反応しないこと（少ないこ と)

(6) 下地との間に歪み等が生じないこと

(7) ステップカバレッジの良いこと

(8) 電気的特性の良いこと（絶縁膜…リーク電 流少，高耐圧，メタル…低抵抗）

(9) 結晶性（Poly-Si, $\mathrm{Al}$ 系のグレインサイズ, 結晶方位, 結晶性のコントロール)

(10) 異物, 異常成長部が無く, ピンホールのな いこと

これらの物性には, 相互に矛盾している項目もあ り，最適化は成長条件，装置などを選択すること により行われる。

CVD膜の性質は, 成膜直後のみでなくデバイ ス上必要なその後の各種熱工程, 薬品処理工程な ぞも考慮し検討することが必要である。

\section{CVD成膜装置}

主要な CVD方法を表 1 に, 成膜装置形態を表 2 に記す。

\section{1 減圧 CVD 法 (LPCVD)}

減圧下で反応を起こさせ, ウェハー上に膜を堆 積させる方法である（使用圧力 0.1 数 $100 \mathrm{Torr}$, 
表 1 各 CVDの特徴

\begin{tabular}{|c|c|c|}
\hline CVD方法 & 特徽 & 志用例 \\
\hline 減圧(熱)CVD & $\begin{array}{l}\text { ·ステップカバレッジが良い } \\
\text { ·膜質が良い（表面反応） }\end{array}$ & $\begin{array}{c}\text { Poly-Si, SiN, } \\
\mathrm{SiO}_{2}\end{array}$ \\
\hline$フ^{\circ}$ ラス マ CVD & $\begin{array}{l}\cdot \text { 成膜温度の低温化 } \\
\text {-成膜速度が速い }\end{array}$ & $\begin{array}{l}\mathrm{SiN} \\
\mathrm{SiO}\end{array}$ \\
\hline 常压 CVD & ·成膜速度が速い & BPSG \\
\hline
\end{tabular}

表 2 代表的な CVD装置形態

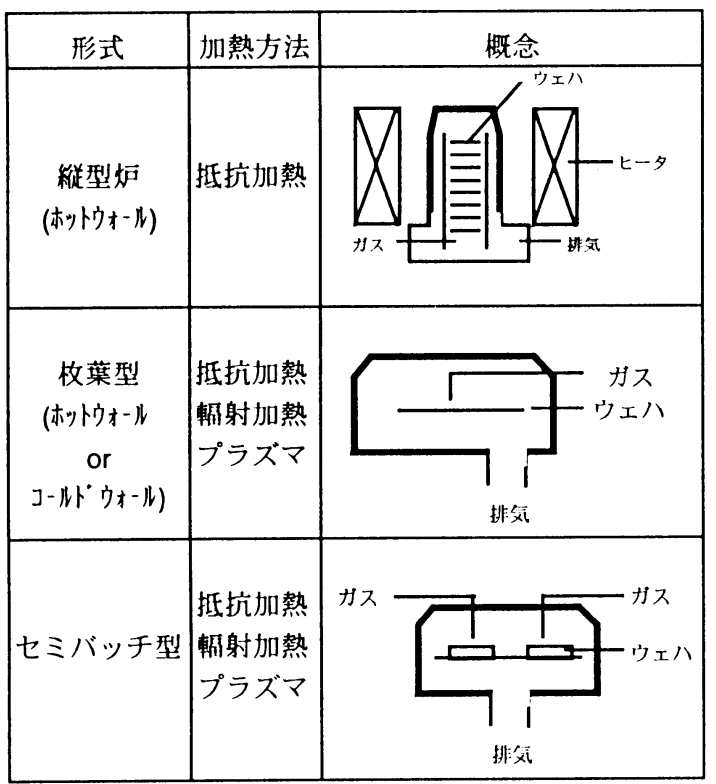

従来の減圧といえば， $0.1 〜 1$ Torr 前後であった が，枚葉機においては，特定のプロセスで 1 Torr 以上の高圧が用いられる)。減压にすることによ り, 反応ガス分子の平均自由行程が長くなり, ガ ス濃度の均一性確保, 気相反応の抑制などが容易 になり，ホットゥォール形態の炉が使用可能となっ た。一般的に言って, LPCVD法は膜の均一性お よび量産性に優れる。

\section{2 プラズマCVD法（P-CVD）}

一般的に0.1 1.0Torr の減圧下で，高周波 (50 $\mathrm{kHz} \sim 2.45 \mathrm{GHz}$ ) を印加し，プラズマを発生させ 膜を堆積させる方法である。

従来は, パッシベーション膜用や層間絶縁膜と して $13.56 \mathrm{MHz}$ を使用し，プラズマ空間にウェハー をさらすプロセスが主流であった。近年は，デバ イス上のニーズにより，プラズマ発生空間と堆積
室を分けた，リモートプラズマを採用する装置も 多く, 膜特性としては, 絶縁膜の低誘電率化や, 埋めこみ特性向上が必要とされ，ハイデンシティー プラズマ（HDP と略す）を利用するむのが多く なった。

\section{3 常圧 CVD法 (APCVD)}

最初に実用化されたCVD法で, 大気圧下で反 応を起こさせるものである。現在では，BPSG， NSGなどの膜に用いられている。

この方法では，膜質および膜厚の均一性を得る ために

1) 原料ガスの大量供給

2 ）基板温度の均一化

が, 重要である。加熱形態としては, ウェハー基 板上のみで，反応を起こすコールドウォールタイ プである。この方法では，ウェハーの大口径化に 伴う均一性の確保，スループット確保が問題とな る。量産装置は, 目的とする膜を形成する上で, 生産性と膜特性を考慮して, 最適なむのが用いら れる。LPCVD（熱）装置は形態上，大きく分け てバッチ処理と枚葉処理に分かれ，一般的に言っ て，バッチ処理は生産性に優れ，枚葉処理は低パー ティクル（異物）化, 高信頼性, 膜厚均一性なよ゙ に特徴がある。

\section{CVD成膜種と使用ガス}

CVDで用いられる膜種と使用ガスを, 現在検 討中のあの屯含めて表 3 に示し, トラジス夕部, 容量部，配線で用いられる代表的な膜（Poly-Si， SiN，BPSG，W）について説明する。

\section{1 Poly-Si}

この膜は, 電極材, 配線材として多くの工程で 用いられる。Poly-Si の堆積には, LPCVD法に よる $\mathrm{SiH}_{4}$ の熱分解（ホットウォール）法が主流 である。アンドープの場合, 成膜温度は, 600〜 $630^{\circ} \mathrm{C}$, 圧力は, $0.1 \sim 0.5 \mathrm{Torr}$ で以下の反応によ り膜が堆積する。

$$
\mathrm{SiH}_{4} \rightarrow \mathrm{Si}+2 \mathrm{H}_{2}
$$

アンドープ Poly-Si のままでは電気抵抗が高い ため, 不純物をドープして用いる。ドープの方法 としては 
表 3 CVD成膜種と使用ガス

\begin{tabular}{|c|c|c|c|c|}
\hline & & 膜種 & 使用力又 & 備考 \\
\hline \multirow[t]{5}{*}{ ゲート } & \multirow[t]{2}{*}{ 絶緑膜 } & $\mathrm{SiO}_{2}$ & $\begin{array}{l}\mathrm{O}_{2} \\
\mathrm{H}_{2} \mathrm{O}\end{array}$ & $\begin{array}{l}\text { この反応は、CVD でなく } \\
\text { 整酸化を用いている。 }\end{array}$ \\
\hline & & $\mathrm{Ta}_{2} \mathrm{O}_{5}$ & $\begin{array}{l}\mathrm{Ta}\left(\mathrm{OC}_{2} \mathrm{H}_{5}\right)_{5} \\
\mathrm{TaCl}_{5}\end{array}$ & $\begin{array}{l}\left.\mathrm{Ta}\left(\mathrm{OC}_{2} \mathrm{H}_{5}\right)_{5} \text { 液体 }\right)-ス \\
\mathrm{TaCl}_{5} \text { 固体ツ-ス }\end{array}$ \\
\hline & \multirow[t]{2}{*}{ 電極 } & Doped-Poly-Si & $\begin{array}{l}\mathrm{SiH}_{4} \\
\mathrm{PH}_{3} \\
\mathrm{Si}_{2} \mathrm{H}_{6} \\
\end{array}$ & \\
\hline & & $\begin{array}{l}\text { WSi } \\
\text { w }\end{array}$ & $\begin{array}{l}\mathrm{WF}_{6} \\
\mathrm{DCS} \\
\mathrm{SiH}_{4} \\
\mathrm{WF}_{6}, \mathrm{H}_{2}\end{array}$ & $\begin{array}{l}\mathrm{TiSi}_{2}, \mathrm{CoSi}_{2} \text { 等は、枌, } \\
\text { 夕ーが主流。 }\end{array}$ \\
\hline & サイドウール & $\begin{array}{l}\mathrm{SiN} \\
\mathrm{SiO}_{2} \\
\mathrm{SiO}_{2}\end{array}$ & $\begin{array}{l}\text { DCS, } \mathrm{NH}_{3} \\
\mathrm{SiH}_{4}, \mathrm{~N}_{2} \mathrm{O} \\
\text { TEOS }\end{array}$ & \\
\hline \multirow[t]{6}{*}{$\neq+1^{\circ}: g^{\prime}$} & \multirow[t]{3}{*}{ 容量膜 } & $\mathrm{SiN}$ & $\begin{array}{l}\mathrm{OCS} \\
\mathrm{NH}_{3} \\
\mathrm{SiH}_{4}, \mathrm{NH}_{3} \\
\end{array}$ & \\
\hline & & $\begin{array}{l}\mathrm{Ta}_{2} \mathrm{O}_{5} \\
\mathrm{TaCl}_{5} \\
\end{array}$ & $\mathrm{Ta}\left(\mathrm{OC}_{2} \mathrm{H}_{5}\right)_{5}$ & \\
\hline & & BST & $\begin{array}{l}\mathrm{Ba}(\mathrm{dpm}) \\
\mathrm{Sr}(\mathrm{dpm}) \\
\mathrm{Ti}(\mathrm{OiPr})_{4}\end{array}$ & $\begin{array}{l}\text { サス種は検討中。 } \\
\text { 代表例を示す。 }\end{array}$ \\
\hline & \multirow[t]{3}{*}{ 電檽 } & Doped-Poly-Si & $\begin{array}{l}\mathrm{SiH}_{4} \\
\mathrm{PH}_{3}\end{array}$ & \\
\hline & & TiN & $\begin{array}{l}\text { 無譏 } \mathrm{Ti} \\
\mathrm{NH}_{3} \\
\text { 有援 } \mathrm{Ti}\end{array}$ & \\
\hline & & $\begin{array}{l}\mathrm{Ru} \\
\mathrm{Ir} \\
\mathrm{Pt}\end{array}$ & $\begin{array}{l}\mathrm{Ru}(\mathrm{dpm})_{3} \\
\mathrm{Ir}(\mathrm{dpm})_{3} \\
\left(\mathrm{C}_{5} \mathrm{H}_{6}\right) \\
\mathrm{Pt}\left(\mathrm{CH}_{3}\right) \\
\end{array}$ & $\begin{array}{l}\text { カス種は榆討中 } \\
\text { 代表例を示す。 }\end{array}$ \\
\hline \multirow{2}{*}{\multicolumn{2}{|c|}{ 絶緑膜 }} & BPSG & $\begin{array}{l}\mathrm{PH}_{3} \\
\text { TEOS/TMB }\end{array}$ & - TEOS/TMB 洨体り- \\
\hline & & $\begin{array}{l}\mathrm{SiO}_{2} \\
\mathrm{SiOF} \\
\text { Low-K } \\
\end{array}$ & $\begin{array}{l}\mathrm{SiH}_{4} \\
\mathrm{SiH}_{4}, \mathrm{~F}_{2} \\
\text { 有譏り- } 2\end{array}$ & $\begin{array}{l}\text { 利用ソース、成膜方法 } \\
\text { 検封中。 }\end{array}$ \\
\hline \multirow[t]{4}{*}{ 配線 } & 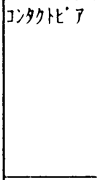 & $\begin{array}{l}\text { W } \\
\mathrm{TiN} \\
\mathrm{Ti} \\
\mathrm{Al} \\
\mathrm{Cu}\end{array}$ & 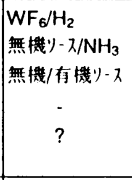 & 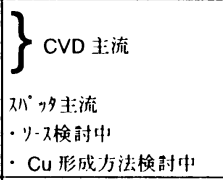 \\
\hline & 配䅨 & $\begin{array}{l}\mathrm{Al} \\
\mathrm{Cu}\end{array}$ & ? & $\begin{array}{l}\text { Al スパッ夕 } \\
\text { Cuソース検封中 }\end{array}$ \\
\hline & 屏開絶絯 & $\begin{array}{l}\mathrm{SOG} \\
\mathrm{SiO}_{2} / \mathrm{SiOF} \\
\mathrm{LOW}-\mathrm{K} \\
\end{array}$ & $\begin{array}{l}\text { 有櫵材料 } \\
\mathrm{SiH}_{4} / \mathrm{F}_{2} \\
\text { 有譏材料 }\end{array}$ & $\begin{array}{l}\cdot \text { 盗功 } \\
\cdot \operatorname{HDP}\end{array}$ \\
\hline & バリアメター & $\begin{array}{l}\text { WN } \\
\text { TiN } \\
\text { TaN }\end{array}$ & 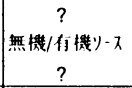 & 成膜方法検討中 \\
\hline 保绕膜 & & $\begin{array}{l}\mathrm{SiN} \\
\mathrm{SiO}\end{array}$ & $\begin{array}{l}\text { TEOS } / \mathrm{NH}_{3} \\
\text { TEOS }\end{array}$ & P-CVD \\
\hline
\end{tabular}

1）アンドープ Poly-Si 堆積イオン注入（この 後, 活性化アニールが必要)

2) in-situ 不純物ドープ

の 2 通りがある。近ごろは，2）の in-situ法が 多くなってきた。

この方法は上記の反応による膜堆積中に目的と する不純物ガスを添加する（nタイプには P, As, ドープ，PタイプにはBドープ）方法であり，
Poly-Si 堆積と同時に不純物が導入でき，プロセ スステップを減らすことが可能である。

あう 1 つ, 最近の特徵は, 使用される膜がPolySi より $\alpha-S i$ が多く用いられ始めたことである。 この場合，成膜温度を $500 \sim 600^{\circ} \mathrm{C}$ に下げること だけで膜堆積が可能である。 $\alpha-S i$ 膜成膜速度向 上のため, $\mathrm{Si}$ ソースとして $\mathrm{Si}_{2} \mathrm{H}_{6}$ などの検討も 行われている。

\section{6. $2 \mathrm{Si}_{3} \mathrm{~N}_{4}$}

$\mathrm{Si}_{3} \mathrm{~N}_{4}$ 膜は, マスク用, キャパシタ容量膜 (LPCVD主流), また, 最終パッシベーション膜 （P-CVD）として用いられる。LPCVD法を利用 した成膜方法として (LPCVD法), 以下の 2 通 りの反応がある。

$$
3 \mathrm{SiH}_{2} \mathrm{Cl}_{2}+4 \mathrm{NH}_{3} \rightarrow \mathrm{Si}_{3} \mathrm{~N}_{4}+6 \mathrm{HCl}+6 \mathrm{H}_{2}
$$

$$
3 \mathrm{SiH}_{4}+4 \mathrm{NH}_{3} \rightarrow \mathrm{Si}_{3} \mathrm{~N}_{4}+12 \mathrm{H}_{2}
$$

(1) の反応は, 温度 $700 \sim 800^{\circ} \mathrm{C}$, 圧力 $0.1 \sim 1.0$ Torr

(2) の反応は, 温度 $800 \sim 900^{\circ} \mathrm{C}$, 圧力 $0.1 \sim 0.5$

Torr で堆積される。

(1) の反応による方法の特徴は, 膜厚の均一性が 非常に良く, 量産性に優れるが, 副生成物を発生 し，パーティクルの原因となる。一方，(2) の反 応による方法は, 供給律速の反応で膜均一性を得 るのは難しいが, 副生成物を作らないという利点 がある。これらの特徴を考慮して, 各メーカーで 成膜方法を選択している。

$\mathrm{Si}_{3} \mathrm{~N}_{4}$ は, 非常に安定した膜であり, 耐酸化性, 耐透過性に優れるが, 問題は $1 \times 10^{10} \mathrm{dyn} / \mathrm{cm}^{2}$ の メタル並みのストレスである。

\section{3 BPSG (boron-phosphosilicate glass)}

この膜は，一般的に常圧 CVD法で堆積される。 成膜温度 $<500^{\circ} \mathrm{C}$ 。用途としては, ゲートと上部 配線間の絶縁膜として用いられ，プロセス的には， 埋め込み特性が求められる。Si ソースとしては, TEOS(tetraethylorthosilicate)。Pソースとして

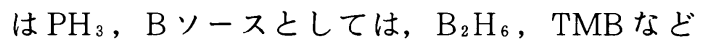
が用いられる。

- $\mathrm{TEOS}+\mathrm{O}_{2} \rightarrow \mathrm{SiO}_{2}+$ 副生成物

- $4 \mathrm{PH}_{3}+5 \mathrm{O}_{2} \rightarrow 2 \mathrm{P}_{2} \mathrm{O}_{5}+6 \mathrm{H}_{2}$ 
- $\mathrm{B}_{2} \mathrm{H}_{6}+3 / 2 \mathrm{O}_{2} \rightarrow \mathrm{B}_{2} \mathrm{O}_{3}+3 \mathrm{H}_{2}$

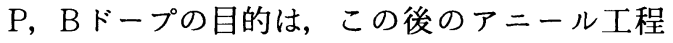
において, リフロー特性を良くすることである。 P，Bは, 約数 atmic\%ドープされる。ドープ量 が多いと, 低温でリフローを始めるが, 高濃度に なるほど, 吸湿性が増し, 水分と反応して $\mathrm{Al}$ 配 線腐食の原因となる。このトレードオフを考慮し て, P, Bのドープ量が決められる。近年は, リ フロー工程の温度（ $850^{\circ} \mathrm{C}$ ) が問題となり, 他 種膜利用の動きも盛んである。

\section{6. $4 \mathrm{~W}$}

水素還元法による $\mathrm{W}$ 膜の成膜は, 温度 $<500^{\circ} \mathrm{C}$, 反応式は以下のようになる。

$$
\mathrm{WF}_{6}+3 \mathrm{H}_{2} \rightarrow \mathrm{W}+6 \mathrm{HF}
$$

$\mathrm{W}$ の用途は，現在，ビアが主流であり，プロセ ストレンドとしては低温化, CMP 対応のレベル コントロールが求められている。

以上，代表的な成膜方法を記したが，これ以外 のソースガスと成膜方法で同じ膜を堆積している ケースも多くある。これは, CVD法のメリット の 1 つであるがソースガスや成膜方法を変えるこ とにより，膜の特性を変えることが可能だからで ある。また，前述の膜はデバイスに残る膜のみを 記したが，これ以外に，使用後取り去られる膜 （例えば露光時に，マスクとして使用される膜） ああり，CVD膜の用途は更に多岥に渡る。 最近のCVDソーストレンドは ・気体ソース $\rightarrow\left\{\begin{array}{l}\text { 液体ソース } \\ \text { 固体ソース }\end{array}\right.$ ガス分解は「熱」が主流
・無機ソース $\rightarrow$ 有機ソース

への移り変わりが見える。

\section{7. おわりに}

今後のCVD技術としては，デバイス側からの ニーズとして

1) 低温化 サーマルバジェットの低減

2 ）プロセス高精度化

薄膜化が進む中, $0.1 \mathrm{~nm}$ での制御性が必要。 In-situ Monitor 等の採用

3 ) 新材料の採用

メタル化の促進（低抵抗化）

4 ）生産コスト低減

$$
\text { ダミウェハー等の削減 }
$$

が求められると考える。

今後, 半導体デバイスの構造が複雑化かつ縮小 化の一途をたどる内で，生産性と膜質に優れる CVD成膜方法は，今後ますます重要性が増すす のと考える。

(1998-4-20 受理)

\section{文献}

1 ）前田和夫 ; 最新 LSI プロセス技術, p. 221（工業 調查会, 1985) 